\title{
DEFECTS IN IDENTIFYING OBJECTS VISUALLY IN A PATIENT WITH CEREBROVASCULAR DISEASE
}

BY

\author{
G. ETTLINGER and MARIA WYKE
}

From the Psychological Laboratory, Institute of Neurology, London

It has been suggested that the condition associated with disease or injury of the brain in which ability to identify objects is impaired may in certain cases be regarded as a true failure of recognition. Such was the conclusion of Jackson (1876) when he reported a case of 'imperception', of Munk (1877) when he described 'mind blindness' in dogs, of Lissauer (1890) when he distinguished between 'apperceptive' and 'associative' mind blindness, and of Freud (1891) when he proposed the term 'agnosia' for cases having defective 'object-concepts'. Although many authors of the present century (notably Liepmann, 1908; Lange, 1936; Brain, 1941; Hécaen and Ajuriaguerra, 1956) have similarly held that the process of object recognition itself may become disordered, contrary opinions have not been wanting. Thus, Bay $(1950,1953)$ has argued that in the majority of published cases intellectual deterioration together with subtle sensory changes can be held responsible for defective identification of objects. This view has found wide acceptance (cf. Critchley, 1953; Teuber, 1955), although little evidence in its favour was forthcoming from one recent investigation (Ettlinger, 1956).

It is our purpose to describe a condition resembling visual object agnosia. This report is made for the following reasons: First, the ability of our patient to identify objects by vision, by touch, or by both together, was investigated quantitatively; secondly, his vision was examined with a number of techniques claimed to be relevant to the problem of visual object agnosia; and finally, his intellectual level was assessed by standard psychometric methods.

\section{Case Report}

Clinical History.-A storekeeper (F.C., N.H. 84776), aged 59, was admitted to the National Hospital, Queen Square, on January 8, 1960, under the care of Dr. Marshall. Five years previously he had had an attack of vertigo and of numbness of the left side of the face and weakness of the right leg. He made a good recovery and stayed well until February, 1959, when he had another attack of giddiness and numbness of the left side of the body, with weakness of both legs: this again gradually improved. A week before admission he began to have severe headaches, and three days later he complained ofw visual difficulties. Two days before admission he became confused and had some difficulty in expressing what he wanted to say. He did not take to his bed, nor did he vomit or lose consciousness.

Clinical Examination.- - He was a right-handed map with blood pressure of $210 / 115 \mathrm{~mm}$. Hg. No othen abnormalities were found except on examination of tbe central nervous system.

Although he was moderately disorientated in space a d $\gg$ time (but not for person) he was cooperative. He constantly minimizing his troubles and lacked insight into his difficulties. His identification of objects defective. There was a nominal dysphasia, he was unable to read, and there was a disorder of writing. Howe he was a good subject on neurological examination.

Examination of the visual fields demonstrated a ris homonymous hemianopsia. His considerable loss. of acuity in both eyes could not be accurately assessed. N\& abnormalities were seen in the fundi, apart from some arteriovenous nipping. There was no diplopia of nystagmus. Both pupils were small and reacted sluggishl to light. The other cranial nerves were normal.

There was mild weakness and increase of tone of the right arm and leg, with some incoordination. The right plantar response was extensor. There was no sensors abnormality on neurological testing.

The presumptive diagnosis of cerebrovascular diseas (brain-stem ischaemia) was made, and he was given. anticoagulant therapy.

Investigations.-On January 8, 1960, the urine was normal. Haemoglobin was 16.2 g. \%; W.B.C. 5,600 peio c. mm.; E.S.R. $2 \mathrm{~mm}$. in one hour. Blood urea waş. $16 \mathrm{mg} . \%$ and serum cholesterol $166 \mathrm{mg} . \%$. The Wasser mann reaction was negative in the cerebrospinal fluid ans blood. Cerebrospinal fluid pressure was $130 \mathrm{~mm}$. C.S.F on January 13, 1960. The fluid appeared clear an colourless, no cells were seen, and the protein wass $30 \mathrm{mg} . \%$.

A soft tissue swelling in the scalp was the onl abnormality on radiographs of the skull (Dr. J. W. D? Bull). An E.E.G. on January 12 (Dr. P. Bladin) gaved evidence of 'a structural abnormality on the left siden 
which is giving abnormal activity over the whole of the side of the head'.

Progress.-The patient slowly improved during his time in hospital, so that he had very little difficulty in using his right limbs. The dysphasia and field defects persisted. He was discharged on January 7, 1960. Information was obtained in February, 1961, that his condition had deteriorated on account of a further cerebrovascular accident, but no further details are available.

Psychological Examination.-The patient was seen on a number of occasions by different examiners. The results of intellectual testing (Dr. J. McFie) on the Wechsler Bellevue scale (form I) were uneven (Table I). His scores

TABLE 1

WEIGHTED SCORES OF F.C. ON SUBTESTS OF WECHSLER BELLEVUE INTELLIGENCE TEST

\begin{tabular}{l|c|c}
\hline \multicolumn{1}{c|}{ Subtest } & $\begin{array}{c}\text { Weighted } \\
\text { Scores }\end{array}$ & $\begin{array}{c}\text { Mean for } \\
\text { Age 59 }\end{array}$ \\
\hline Vocabulary & 13 & $9 \cdot 5$ \\
Arithmetic & 7 & 6.9 \\
Similarities & 7 & 7.9 \\
Digit span & 6 & $7 \cdot 5$ \\
Picture completion & 9 & 7.4 \\
Block design & 5 & 6.7 \\
\hline
\end{tabular}

on the vocabulary and picture completion tests were above the average level. Scores on other tests were about average, except in the case of block designs where the score was below this level. His overall intellectual efficiency was found to be about average for his age and this probably represented moderate deterioration from a level that had been higher before his illness. These findings were confirmed by his failure to learn the Babcock sentence in seven attempts and by his poor performance on the Terman memory for designs test and on tests of drawing and construction with match sticks.

His performance on tests of praxis (Professor O. L. Zangwill) was normal except for one instance of misuse of an object. There was no evidence of receptive or expressive dysphasia, but he had mild nominal difficulties and in addition a disorder of writing. His visual orientation in space was preserved.

His performance with other kinds of visual material was also tested (on January 26, 1960). He made eight errors in 12 attempts when asked to give the names of primary colours (not shades) shown to him. These were not entirely dysphasic errors for he still made three errors in 12 attempts when asked to select the names of the same colours from among four alternatives (including the correct name) given him for each colour. Similarly he made four errors in 12 attempts when required to point to colours to command. Asked to give the colours of common objects, e.g., pillar box, sun, coal, salt, etc., he made only one mistake in $\mathbf{2 6}$ attempts (giving blue as the colour of the sun). He was correct in six out of nine attempts to find the colour appropriate to an object, e.g., point to the colour of grass, of a roof, etc.

Tested with 10 outline pictures of common objects (taken from the picture vocabulary test of the TermanMerrill scale) he made nine errors, of which only one was obviously dysphasic. At the same time he was able to discriminate accurately between forms (see section on examination of visual efficiency). Tested with more complex pictures on January 14, 1960, by Professor O. L. Zangwill, he gave very poor descriptions; however, he accurately indicated specific items on request.

Psychiatric Examination.-Dr. R. T. C. Pratt examined the patient on January 26, 1960, when he was found to be disorientated in time and place. His memory for events in his early life was poor. He was thought to be a little too eager to please the examiner, rather than having any tendency to exaggerate his disabilities.

Examination of Visual Efficiency.-In Fig. 1 are shown the patient's visual fields charted on a tangent screen with $1 \mathrm{~mm}$., $2 \mathrm{~mm}$., $1 \mathrm{~cm}$., and $2 \frac{1}{2} \mathrm{~cm}$. targets. He was also
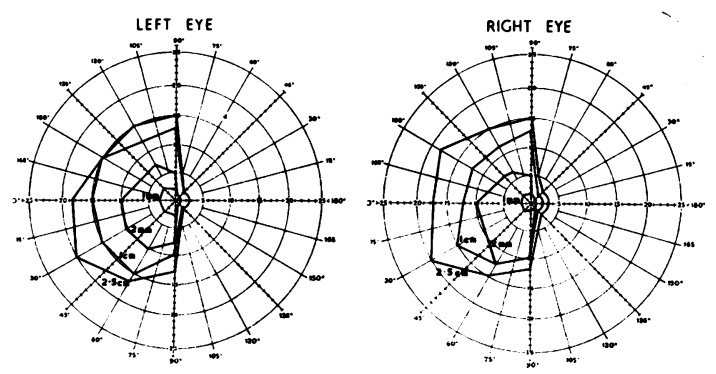

Fig. 1.-Visual fields in F.C. taken with $1 \mathrm{~mm}$., $2 \mathrm{~mm}$., $1 \mathrm{~cm}$., and $2 \frac{1}{2} \mathrm{~cm}$. targets on the tangent screen.

examined on tests of relative brightness discrimination, flicker fusion, and local adaptation at representative points in his left half visual field and in central vision. (Reasons for using these tests, and a detailed description of the methods of examination are to be found elsewhere, Ettlinger, 1956). The methods and test conditions of the earlier study have been exactly reduplicated in examining our case F.C. Therefore the 'normal' values, presented in the earlier report that refer to the middle $80 \%$ of results for the two eyes of the $\mathbf{4 8}$ healthy control subjects may also be used here.

The test results at brightness discrimination, flicker fusion, and local adaptation for F.C. are shown in Figs. 2, 3 , and 4 in relation to these 'normal' values. The symbol $\sqrt{ }$ in Figs. 2 and 3 refers to thresholds at brightness discrimination or flicker fusion that fall within the 'normal' range of values for a given position in the visual field. The figures preceded by the minus sign indicate in Fig. 2 the degree of impairment of brightness discrimination in F.C. The more negative values indicate a greater degree of impairment (higher thresholds). The figures refer to the number of steps (related to $0.25 \mathrm{log}$. units of light transmission) that the relevant threshold in F.C. is above the upper limit of the 'normal' values. Similarly the figures preceded by the minus sign in Fig. 3 indicate the degree of impairment of flicker fusion in F.C. Again the more negative values indicate a greater degree of impairment (lower fusion frequencies). The figures refer to the number of cycles per second that the relevant fusion 


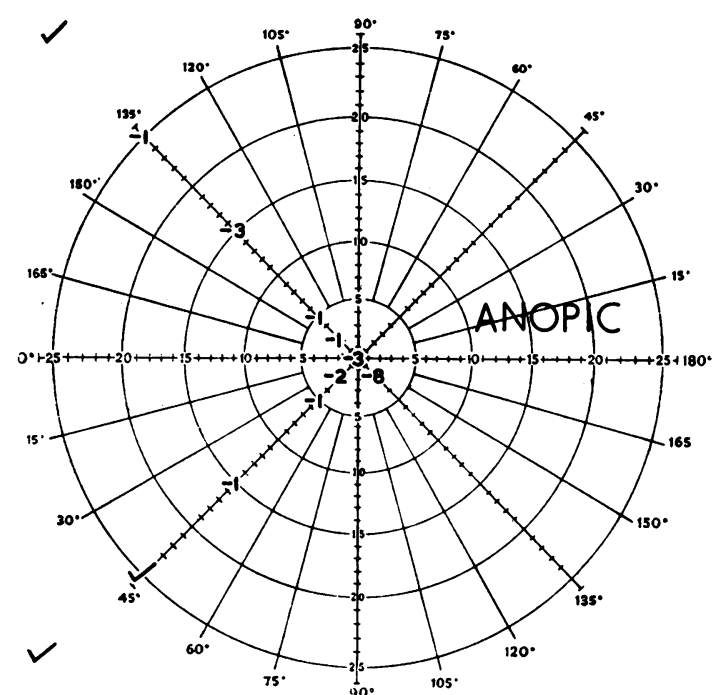

FIG. 2.-Thresholds for left eye of F.C. obtained on a test of brightness discrimination on January 20, 1960.

threshold (mean of four readings) in F.C. is below the lower limit of the 'normal' values. In Fig. 4 there are no figures preceded by a minus sign. This is because all the results at local adaptation in F.C. fell within the range of 'normal' values. The figures in this test indicate the duration in seconds of the middle one of three fading times taken at each position in the visual field.

It is seen that there is a mild degree of impairment on tests of brightness discrimination and of flicker fusion (Figs. 2 and 3 ) but not on the test of local adaptation. In interpreting the results on the former two tests it should be remembered that $10 \%$ of values from healthy subjects would be taken to show impairment (and frequently as

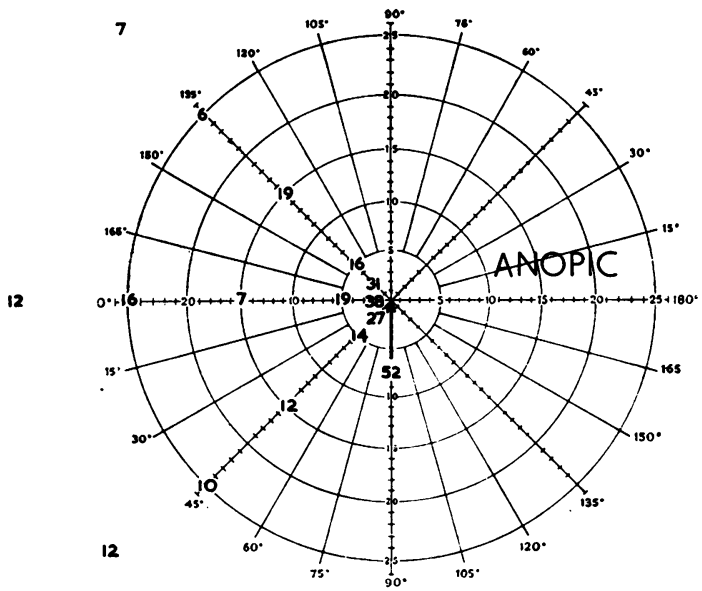

Fig. 4.-Fading times for left eye of F.C. obtained on a test of local adaptation on January $21,1960$.

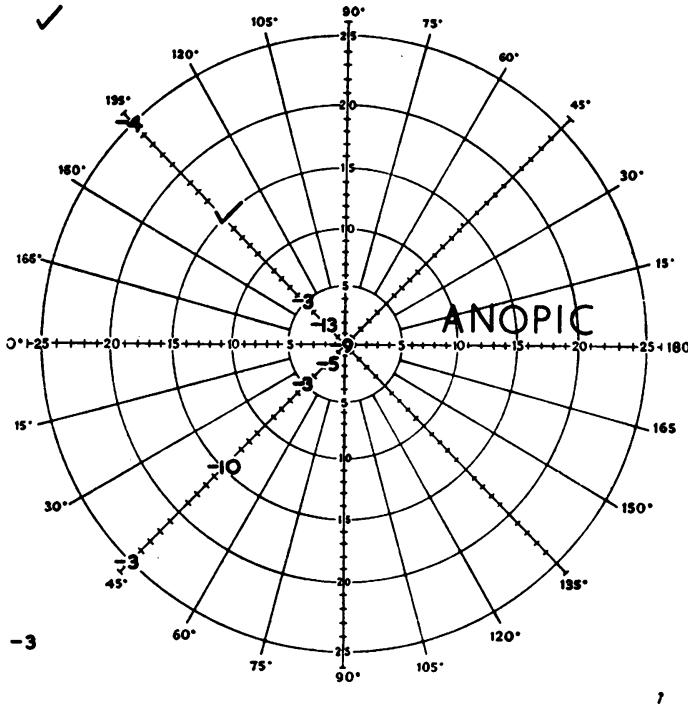

FIG. 3.-Fusion frequencies for left eye of F.C. obtained on a test of flicker fusion on January $21,1960$.

severe as that in F.C.) merely because the 'normal' limis $\omega$ refer to only the middle $80 \%$ of all normal val obtained.

The patient was also tested on January 22 for his abi奥y to match outline shapes, following the procedure used $8 y-$ Brain (1941) to establish the basic adequacy of vision 2 his case of visual agnosia. For this purpose we used Ane standardized tests of the Terman-Merrill scale (L) ca遮es discrimination of forms, at the four-year level, a pictorial likenesses and differences, at the $4 \frac{1}{2}$ year levge The patient made no error in 16 attempts with different shapes. He was also required to match a sample againso four alternatives in an unstandardized test of matching irregular forms. There were 10 different sets of irregular forms (each with sample and alternatives) in this test, anफ़ he made no mistakes.

\section{Experimental Examination of Object Identification}

Our patient's faulty identification of objects by vision had been observed immediately on admission, and it had been confirmed during the psychological and psychiatries examinations. Various contributory factors were then investigated. Psychometric testing indicated an adequate level of residual intellectual function despite some deterioration. Visual testing likewise revealed a level of efficiency thought to be sufficient for object perception? despite some loss. One problem remained: Was the patient's ability to identify objects by touch genuinelye superior to his visual identification? We were able too answer this question as a result of the following investigation.

Twenty-one objects divided into three groups of familiar, less familiar, and unfamiliar objects (Tables IIN III, and IV) were presented to the patient. Every object was twice presented for identification under each of three conditions, namely, vision alone, touch alone, or vision 
and touch (both hands). Thus our patient made 126 attempts at identification. The 21 objects were presented under the three conditions in random order, and a different random order was used for the second series of 63 attempts.

The patient was asked to name the object. Any response other than the correct name was treated as an error. A time limit of $1 \mathrm{~min}$. was imposed for each object. If his identification was incorrect before the time limit was reached he was asked to guess again what the object might be. The time taken for a correct identification (if less than $1 \mathrm{~min}$.) was recorded with a stop-watch.
Results.- The results of this investigation are shown in Tables II, III, and IV. There were 26 errors with vision alone, 16 with vision and touch, and nine with touch alone (combining the results for all 21 objects). Statistical comparison between the performance under conditions of vision alone and of touch alone indicates that object identification by vision is significantly more impaired than it is by touch $\left(x^{2}=14 \cdot 17, \mathrm{P}<0.001\right)$.

The similar comparison between performance under conditions of vision alone and of vision and touch together indicates that identification by vision alone is significantly more impaired than it is by vision and touch

TABLE II

IDENTIFICATION OF FAMILIAR OBJECTS

\begin{tabular}{|c|c|c|c|c|c|c|}
\hline Object & By Vision & $\underset{\text { (Sec.) }}{\text { Time }}$ & By Touch & $\begin{array}{l}\text { Time } \\
\text { (Sec.) }\end{array}$ & By Vision and Touch & $\begin{array}{l}\text { Time } \\
\text { (Sec.) }\end{array}$ \\
\hline $\begin{array}{l}\text { Spoon } \\
\text { Cup } \\
\text { Pen } \\
\text { Glasses } \\
\text { Glove } \\
\text { Watch } \\
\text { Book }\end{array}$ & $\begin{array}{l}\text { For cooking } \\
\text { Put milk } \\
\text { For dressmaking } \\
\text { Pen writer } \\
\text { Fuse tape } \\
\text { Eye glasses } \\
\text { Wristwatch } \\
\text { A box } \\
\text { For hands } \\
\text { Not a scarf } \\
\text { Stopper } \\
\text { Book } \\
\text { Book }\end{array}$ & $\begin{array}{r}60 \\
60 \\
10 \\
60 \\
60 \\
60 \\
5 \\
60 \\
15 \\
40 \\
60 \\
15 \\
15 \\
4\end{array}$ & $\begin{array}{l}\text { Spoon } \\
\text { Spoon } \\
\text { Jug } \\
\text { Cup } \\
\text { Writing pencil } \\
\text { Fountain pen } \\
\text { Glasses } \\
\text { Glasses } \\
\text { Glove } \\
\text { Glove } \\
\text { Watch } \\
\text { Wristwatch } \\
\text { Book } \\
\text { Book }\end{array}$ & $\begin{array}{r}2 \\
10 \\
58 \\
7 \\
60 \\
4 \\
5 \\
3 \\
7 \\
40 \\
12 \\
5 \\
4 \\
10\end{array}$ & $\begin{array}{l}\text { Spoon } \\
\text { Spoon } \\
\text { For carrying water } \\
\text { Jug } \\
\text { Fountain pen } \\
\text { Fountain pen } \\
\text { For putting on } \\
\text { Compass } \\
\text { Spoon } \\
\text { Glove } \\
\text { Wristwatch } \\
\text { Wrist key } \\
\text { Book } \\
\text { Key }\end{array}$ & $\begin{array}{r}7 \\
2 \\
58 \\
45 \\
12 \\
4 \\
35 \\
45 \\
7 \\
5 \\
4 \\
40 \\
2 \\
6\end{array}$ \\
\hline
\end{tabular}

TABLE III

IDENTIFICATION OF LESS FAMILIAR OBJECTS

\begin{tabular}{|c|c|c|c|c|c|c|}
\hline Objects & By Vision & $\begin{array}{c}\text { Time } \\
\text { (Sec.) }\end{array}$ & By Touch & $\begin{array}{c}\text { Time } \\
\text { (Sec.) }\end{array}$ & By Vision and Touch & $\begin{array}{l}\text { Time } \\
\text { (Sec.) }\end{array}$ \\
\hline $\begin{array}{l}\text { Padlock } \\
\text { Rubber } \\
\text { Button } \\
\text { Scissors } \\
\text { Ruler } \\
\text { Key } \\
\text { Bottle }\end{array}$ & $\begin{array}{l}\text { A key } \\
\text { Lockets } \\
\text { Open by key } \\
\text { For weather } \\
\text { Button } \\
\text { Use with a pin } \\
\text { Pen } \\
\text { Scissors } \\
\text { In offices } \\
\text { A measure } \\
\text { Key } \\
\text { Staple } \\
\text { Button } \\
\text { Key }\end{array}$ & $\begin{array}{l}60 \\
60 \\
45 \\
50 \\
60 \\
25 \\
50 \\
40 \\
60 \\
20 \\
45 \\
59 \\
5 \\
40\end{array}$ & $\begin{array}{l}\text { Cigarette } \\
\text { Rubber catch } \\
\text { Indiarubber } \\
\text { Indiarubber } \\
\text { Button } \\
\text { Button } \\
\text { Pair of scissors } \\
\text { Scissors } \\
\text { Ruler } \\
\text { You draw with } \\
\text { Key } \\
\text { Key } \\
\text { Jar } \\
\text { Carrying liquid }\end{array}$ & $\begin{array}{r}45 \\
30 \\
5 \\
6 \\
15 \\
3 \\
15 \\
5 \\
30 \\
60 \\
6 \\
2 \\
7 \\
50\end{array}$ & $\begin{array}{l}\text { Wristwatch } \\
\text { A bottle } \\
\text { Rubber } \\
\text { Rubber } \\
\text { A mark for clothing } \\
\text { Button } \\
\text { Scissors } \\
\text { Scissors } \\
\text { A measure } \\
\text { Key } \\
\text { Key } \\
\text { Ink bottle } \\
\text { Bottle }\end{array}$ & $\begin{array}{r}60 \\
10 \\
4 \\
5 \\
60 \\
5 \\
60 \\
4 \\
60 \\
15 \\
10 \\
35 \\
7 \\
5\end{array}$ \\
\hline
\end{tabular}

TABLE IV

IDENTIFICATION OF UNFAMILIAR OBJECTS

\begin{tabular}{|c|c|c|c|c|c|c|}
\hline Objects & By Vision & $\begin{array}{r}\text { Time } \\
\text { (Sec.) }\end{array}$ & By Touch & $\begin{array}{l}\text { Time } \\
\text { (Sec.) }\end{array}$ & By Vision and Touch & $\begin{array}{r}\text { Time } \\
\text { (Sec.) }\end{array}$ \\
\hline $\begin{array}{l}\text { Box } \\
\text { Wire } \\
\text { Handkerchief } \\
\text { Screw } \\
\text { Cottonwool } \\
\text { Tie } \\
\text { Paint brush }\end{array}$ & $\begin{array}{l}\text { Cardboard box } \\
\text { Box } \\
\text { Fuse wire } \\
\text { Electric tape } \\
\text { Handkerchief } \\
\text { Scarf } \\
\text { Cigarette } \\
\text { Screw } \\
\text { Cottonwool } \\
\text { Tie } \\
\text { Tie } \\
\text { Painting B } \\
\text { Electric plug }\end{array}$ & $\begin{array}{r}4 \\
2 \\
10 \\
15 \\
7 \\
5 \\
45 \\
2 \\
15 \\
60 \\
4 \\
5 \\
35 \\
60\end{array}$ & $\begin{array}{l}\text { Cardboard box } \\
\text { Box } \\
\text { Electric wire } \\
\text { For wood work } \\
\text { Piece of cloth } \\
\text { Material } \\
\text { Screw } \\
\text { Screw } \\
\text { Use in a ... } \\
\text { Cottonwool } \\
\text { Piece of cloth } \\
\text { Tie } \\
\text { Brush for paint } \\
\text { Brush }\end{array}$ & $\begin{array}{r}15 \\
2 \\
10 \\
40 \\
15 \\
15 \\
18 \\
7 \\
60 \\
3 \\
10 \\
17 \\
40 \\
10\end{array}$ & $\begin{array}{l}\text { A box } \\
\text { Flex } \\
\text { Article of dress } \\
\text { Handkerchief } \\
\text { Screw } \\
\text { Screw } \\
\text { Cottonwool } \\
\text { Being scratch } \\
\text { Neck tie } \\
\text { Neck tie } \\
\text { Paint brush } \\
\text { Brush }\end{array}$ & $\begin{array}{r}15 \\
60 \\
55 \\
60 \\
15 \\
8 \\
45 \\
3 \\
3 \\
60 \\
5 \\
4 \\
40 \\
5\end{array}$ \\
\hline
\end{tabular}


together $\left(x^{2}=4.7, \mathrm{P}<0.05\right)$. However, the remaining comparison indicates that the difference between identification by vision and touch together ( 16 errors) and by touch alone (nine errors) is not significant $\left(\chi^{2}=2 \cdot 79\right.$, $P>0.05)$.

A qualitative analysis of the mistakes made by our patient indicates various kinds of error of identification.

Dysphasic Errors.-Dysphasic errors, when the patient failed to give the correct name of an object but nevertheless appeared to recognize it by giving its use or a paraphasic name. There were 12 dysphasic errors when objects were presented for visual identification, six when for tactile identification, and eight when both vision and touch were permitted. When a comparison is made between object identification by vision alone and by touch alone after all dysphasic errors have been excluded, visual identification is still found to be significantly more impaired than tactile identification $\left(\chi^{2}=10.52, \mathrm{P}<\right.$ 0.001).

Perseverative Errors.-Perseverative errors were of three kinds. First, there were simple perseverations of the name of an object previously presented and correctly identified. Thus a knife (presented after a fountain pen) was identified as a fountain pen. Secondly, there were more indirect perseverative errors when the name given to an object was related to the use of another object already presented. Thus a paint brush (presented after a piece of fuse wire) was identified as an electric plug. Thirdly, there were repetitive perseverative responses, where a single word, e.g., staple, was repeatedly given at the beginning of various responses to a series of different objects.

Failure in Identification.-The failure of identification was not consistent. There were only a few objects that our patient was unable to identify on both of the two attempts under the same test conditions. We found five such objects on visual testing (padlock, rubber, ruler, bottle, and glove). This result might imply a certain degree of consistency in his failure to identify objects by vision. However, five of these 10 errors, relating to three of the five objects, were dysphasic and not perceptual errors, e.g., a ruler was identified as 'in office' and 'a measure' on successive attempts. Similarly there were three objects (padlock, cup, and glasses) that were incorrectly identified by vision and touch together on both attempts. Three of the six errors, relating to two objects, were dysphasic in origin. There was only one object (padlock) that he failed to identify on both attempts by touch alone. Thus there is little if any evidence to suggest that failure of identification was consistently related to certain particular objects.

We have also been unable to find a meaningful relationship in our case between failure of identification and the degree of familiarity with the objects. These were allocated to their groups (familiar, less familiar, and unfamiliar) by agreement between three examiners on the basis of their frequency of usage. There were fewer (rather than more) errors with the unfamiliar objects than with the familiar ones. Finally, we were able to observe (mainly during less systematic investigations than the one we have described) that on rare occasions the patient was으 unable to identify an object by touch but gave a correct $Z$ answer when the same object was soon afterwards presented for identification by vision and touch.

\section{Discussion}

We are unable to give further information concerning the extent of the brain lesion in our patient. Though the initial attacks were indicative of a brainstem lesion the subsequent history and physical signs indicated that there was a diffuse pathology, pre- $\overrightarrow{\bar{F}}$ sumably ischaemic in nature and due to cerebral atherosclerosis. However, it should be recalled in this connexion that a right homonymous hemianop- $\frac{\bar{\sigma}}{\overline{\bar{n}}}$ sia (with only slight macular sparing) was found to $\frac{\bar{T}}{}$ be associated with an extensive restriction of the left胥 homonymous fields. This would imply at least? bilateral involvement of the visual system.

We must now consider the relative contributions of confusion, of intellectual deterioration, of dysphasia, $\vec{\omega}$ and of both visual and tactile sensory changes in the origin of the defective object identification.

The confusion, although not severe, was the salient feature of his condition. In itself, the con fusion was not unlike that seen by us in many otherw cases of organic cerebral pathology. (We have, ho ever, never seen a case of confusion with differenta involvement of visual and tactile object identifig్ tion.) The test results indicated that our patient of above average intelligence before his illness, bयु등 his impairment brought him to a level of intellect functioning (as assessed by these tests) that was abotit average for his age. Therefore the confusion, hardly the dementia, may be considered to have con:tributed to his failures in object identification.

As well as being confused, our patient was dysphasic. The nature of his errors indicated that he was suffering from a mild nominal dysphasia. How ever, he was able to obey all commands and com $\frac{2}{2}$ prehend fairly complicated material, and his speech was almost normal in casual conversation. It has been suggested by Pötzl (1928) that the names of colours may be selectively lost ('colour aphasia') as a manifestation of dysphasia but we know of no suggestion more recent than that of Freund (1889 that the names of objects perceived by vision, bup not by touch, may be selectively lost in dysphasia Moreover we found a significant superiority of tactile object identification, even after all such errors as were thought to be dysphasic in origin had been excluded from the analysis. We may therefore sup? pose that, while some errors of object naming werd related to the nominal dysphasia, the defective visua王. identification was independent of any dysphasios disability.

The residual vision was assessed in a number of 
ways. From the fields on the tangent screen it appears to consist of a small area (tunnel vision) comprising mainly the macular portion of the field, somewhat offset to the left. However, it might be recalled that similarly extensive constriction of the visual fields does not necessarily cause faulty object identification (Teuber, Battersby, and Bender, 1960). Other tests either gave normal results for the left half field (local adaptation) or only slight reductions from normal values (brightness discrimination, flicker fusion). Finally, our patient was able to match and compare forms without mistakes. We cannot, therefore, explain the impaired visual identification of objects in this case by reference solely to the defect of vision.

Tactile sensibility was judged to be normal in both hands by the use of the standard clinical test methods.

It could be argued that careful quantitative testing might have revealed some subtle alterations of tactile function but it seems unlikely that such tactile changes could have been comparable in severity to the visual loss. Therefore we may infer on the available evidence that visual function was more severely impaired than tactile.

It is evident that no single one of the factors already discussed, e.g., confusion, dysphasia, visual defect, can account for the impaired object identification. We suggest that the confusion in our case was the predominant determinant of impairment of object identification. This, together with the dysphasia, would account for the appreciable number of errors made during object identification by touch alone, even though on clinical testing there was in this sense modality no loss of (tactile) sensibility. When the confusion and dysphasia were combined with some measure of visual disability, a significantly greater number of errors during visual object identification resulted. When tested under conditions of vision and touch combined, the number of errors was greater than with touch alone. This might be because the visual disturbance served actively to disrupt, instead of merely failing to improve, the performances based upon touch. We therefore propose that the considerable degree of confusion, taken together with some measure of visual disturbance, gave rise to a condition resembling visual object agnosia in our patient F.C. In making this proposal we do not wish to imply that confusion was a major factor in previously reported cases of visual object agnosia. Nor can we, on the evidence available to us, either accept or reject the claims of others to have observed agnosia in the sense of a genuine disorder of recognition. Rather we would stress the importance of the systematic (and if possible quantitative) evaluation of object identification, and also of psychometric and visual performance in cases of suspected agnosia.

\section{Summary}

A systematic examination of the defects of visual object identification in a patient with cerebrovascular disease is reported. The patient was required to identify 21 objects twice under three conditions: by vision alone, by touch alone (both hands), and by vision and touch together. He was allowed one minute to give the correct name of each object.

His intellectual functions were also assessed with standard psychometric methods, and his vision was examined on the tangent screen and on tests of brightness discrimination, flicker fusion, and local adaptation. In addition he was given comprehensive neurological, psychological, and psychiatric examinations.

Object identification by vision alone was found to be significantly inferior to identification of the same objects by touch alone or by vision and touch. The relative contributions of confusion, intellectual deterioration, dysphasia, and sensory changes to the impairment of object identification are discussed. It is concluded that confusion together with visual defect caused a condition resembling visual object agnosia.

We are greatly indebted to Dr. J. Marshall for his generous permission to study and report the case of F.C., and for his help in the preparation of this paper. Dr. E. T. O. Slater provided facilities for this work. We also gratefully acknowledge financial assistance to one of us (M.W.) provided by the Mental Health Research Fund. Dr. J. McFie gave valuable help during the investigation. Finally we would like to thank Dr. R. T. C. Pratt and Professor O. L. Zangwill for their helpful comments and suggestions during the preparation of this paper, and Mr. A. H. Pricket, of the Photographic Department, for preparing the figures.

\section{REFERENCES}

Bay, E. (1950), Agnosie und Funktionswandel. Springer, Berlin. Brain, W. R. Brain, 76, 515.

Critchley, M. (1953). The 64, 43.

(1956). The Parietal Lobes. Arnold, London.

Ettlinger, G. (1956). J. Neurol. Neurosurg. Psychiat., 19, 297. S. (1891). Zur Auffassung der Aphasien. Deuticke, Leipzig English translation, On Aphasia (E. Stengel). Imago Publishing

Co., London (1953).
Freund, C. S. (1889). Arch. Psychiat. Nervenkr., 20, 276 and 371, quoted by Freud, S. (1891); Engl trans. (1953) p. 80.

Hécaen, H., and Ajuriaguerra, J. de (1956). Rev. Neurol., 94, 222. Jackson, J. Hughlings (1876). Roy. Lond. ophthal. Hosp. Rep., 8, 434. Lange, J. (1936). In Bumke, O. and Foerster, O. Handbuch der Neurologie, Vol. 6, p. 807. Springer, Berlin.

Liepmann, H. (1908). Neurol. Zbl., 27, 609.

Lissauer, H. (1890). Arch. Psychiat. Nervenkr., 21, 222.

Munk, H. (1877). Verh. physiol. Ges. Berlin, No. 16, 30.3.77.

Pötzl, O. (1928). Die Aphasielehre vom Standpunkte der klinischen Psychiatrie, Vol. 1. Deuticke, Leipzig and Wien.

Teuber, H. L. (1955). Ann. Rev. Psychol., 6, 267. Battersby, W.S., and Bender, M. B. (1960). Visual Field Defects after Penetrating Missile Wounds of the Brain. Harvard Univ. Press, Cambridge, Mass. 